\title{
Diagramming Language for Process Documentation
}

\author{
Sabah Al-Fedaghi \\ Computer Engineering Department - Kuwait University \\ Kuwait \\ sabah@alfedaghi.com \\ Hind Almutairi \\ Information Technology Department - Central Bank of Kuwait \\ Kuwait \\ hind-almutairi@outlook.com
}

\begin{abstract}
According to authorities, problems in organizations arise from the fact that employees have difficulties creating a well-defined and understandable process. Process documentation is a way to visualize organizations' processes that can be simulated and modified for maximum efficiency. Typically, processes are fragmental, nameless, and invisible phenomena that result in difficulties creating process documentation. In the software engineering field, unfortunately, efforts to document processes often end up in voluptuous volumes of verbosity. Little previous research has been conducted in the specific area of process documentation, but research has been conducted in the wide areas of process management and business process management. The focus of this paper is on system documentation as a type of process documentation oriented toward explaining how to do a process. We utilize a new diagrammatic language as a foundation for process documentation. Examples are given from computer manuals and captured from actual processes. The resultant description seems to provide a viable approach in process documentation.
\end{abstract}

Keywords: Process Modeling, Process Documentation, Conceptual Model, Diagrammatic Language

Received: 18 May 2018, Revised 23 June 2018, Accepted 30 June 2018

DOI: $10.6025 / \mathrm{pca} / 2018 / 7 / 2 / 56-67$

(C) 2018 DLINE. All Rights Reserved

\section{Introduction}

Understanding physical and cyber processes has become critical to improve the efficiency, effectiveness, and timeliness of design, manufacturing, or commercial activities. Dynamic processes involve multiple software components across multiple institutions and in multiple domains, and involve software, hardware, and networks. Some applications apply multiple data, storage, and computation infrastructures from a range of sources (RSS, Web Services, AJAX, XML, and HTTP) [1]. "As users become reliant on these applications, they would like to understand where, why, and how their results were produced" [1]. 


\subsection{Process Documentation}

The concern of this paper is process documentation. This term originated in 1978 from scientists who stayed in project villages, where they made detailed observations and documented the process of farmers' formation and functioning to learn from implementation experience [2].

Most process-oriented methodologies are meant to record programs as they occur and feed the information back to managers, other researchers, and policy makers to help them better understand the operation of the project. Such information is often needed to validate and approach the program and consequent policy formation. Many IT companies develop excellent processes but fail to document them adequately. Very few techniques are available to quantify the quality and value of process documentation [3].

A process document is a skeleton of the steps necessary to complete a process. It is documentation that cares more about the "how" of implementation than the "what" of the process impact [4]. It is "a complete description of how to execute a given process. ... Can someone, with a reasonable knowledge, find and read the documentation and successfully execute an instance of the process?" [5].

Process documentation is a roadmap for an organization that helps to identify processes and determine how to improve them. It is a means of communicating what the process is [5]. Not documenting a process leads to process being redesigned by someone every time it is repeated. Documented processes facilitate training, which allows for smooth onboarding [4].

Process documentation is essential for managing processes because it assists in eliminating flaws, saving time, decreasing costs, and improving overall quality. Its roles include process improvement, training, and reducing vulnerabilities to key employee process knowledge [5].

\subsection{Problem}

According to Hammer [6], problems in organizations arise from the fact that employees have difficulties creating a well-defined and understandable process. A process crosses the organizational boundaries, either internal or external, and the complexity of describing processes is difficult. "A process modelling is a way to visualize the organizations' processes which can be simulated and modified to give maximum efficiency, regardless of the complexity" [7]. Processes are fragmental, nameless, and invisible phenomena that result in difficulties creating process documentation [8].

Most organizations have recurring tasks that, once learned, work on autopilot and, as they are passed on from one employee to another, often degrade in their efficiency and effectiveness. "These businesses seldom diagram their processes, as they often lack the knowledge, understanding and willingness to invest the time and effort, or a combination of these" [9]. Even the documentation standards that adopt flowcharts (ISO 2017; ANSI 2016) are not being used [9].

In the software engineering field, "unfortunately efforts to document our process often end up in voluptuous volumes of verbosity that sit on the shelf and gather dust" [10]. "There has not been conducted much previous research in the specific area of process documentation, but there is research conducted in the wide area of Process Management and Business Process Management" [8].

A poorly described process may not completely explain or may include distracting information about the process, which can result in failure. "Remarkably, even people who have been working together for a long time, often don't have a common view of the steps in a process" [5]. An essential measure of process documentation is "how easy it is to follow; how well it keeps a consistent level of technical depth; and to what degree it documents and describes an actual process rather than merely duplicating tables, spreadsheets, and metrics" [3].

\subsection{Tools}

Many tools, both old and recent, exist for process documentation, including visualizing processes through process diagrams, e.g., flowcharts, BPMN [11OMG], UML [12], the IDEF0 modeling language IEEE-1320 [13], and entity process models [14]. "A picture really is worth a thousand words. A simple diagram of a process can make that process easier to understand" [10].

\subsection{Aims}

The focus of this paper is on process documentation, which explains how to best conduct a process. We utilize a new diagram 
matic language, called the thinging machine (TM), also called the flowthing machine, which will be reviewed briefly in the next section [15-18] as a foundation for process documentation. The limited number of notions used in the TM and its all-inclusive description that encompasses the cyber-physical system make TM attractive for documentation.

\section{Thinging Machine (TM)}

The TM model is a diagrammatic schema that uses things to represent a range of items (see Figure 1). In general, a TM is thought to be an abstract machine that receives, processes, creates, releases, and transfers things.

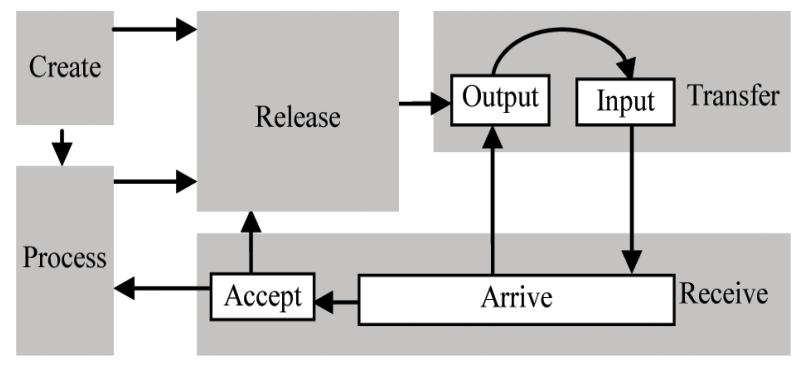

Figure 1. Thinging Machine

Heidegger [19] distinguished between objects and things: A handmade jug can be a thing, while an industrially made can remains an object [19]. For Heidegger [19], things have unique "thingy qualities" [20] that are related to reality.

The term "thinging" refers to "defining a boundary around some portion of reality separating it from everything else and then labeling that portion of reality with a name" [21]. Thinging expresses how "the thing things," which Heidegger [19] explained as "gathering" together its constituents. According to Fry [22], "The thingly character of the thing does not consist in its being a represented object, nor can it be defined in any way in terms of the objectness, the over-againstness, of the object."

Heidegger [19] focused on the ontological thinging of a thing (producing [19] — called creation in the TM). The TM's definition of a thing broadens its characterization, by including other "thingy qualities" [20], i.e., being processed, released, received, and transferred.

In computer science, interest in things and thing-orientation [23] dates back to ThingLab (1979) and the programming language Self (1987). "Thing-oriented programming is the art of creating software composed of Things" [23]. More recently, Water, a prototype-based language, links every XML-tag with its top-level ancestor, "Thing." Additionally, the current field of Internet of things (IoT) is an important development in technical and socio-technical computer science.

TM also utilizes the notion of triggering, which is the activation of a flow, denoted in TM diagrams by a dashed arrow.

In modeling a system, the resultant diagram constructed from TMs (Figure 1) may be called a machine.

\section{Applying the Thinging Machine to Processes}

This section uses two examples in the area of bank applications described in the Procedures Manual that utilizes special types of flowcharts to describe processes.

\subsection{Create a VMWare Virtual Server}

This process in the manual involves a diagram (Figure 2) with no text. The process is given the title "Create a VMWare Virtual Server." The objective is to prepare a platform for isolated applications with the VMWare operating system [24].

\subsubsection{Thinging Machine Static Description}

Fig. 3 shows the TM representation of the process of creating a VMWare virtual server. In the figure, the user makes a request (circle 1) to the IT manager (2); then, the manager signs the forms (3) and sends the request to the system administrator (4). The system administrator creates a virtual machine (VM) through his/her admin interface (5) on a server (6). 
A VMWare is created on the server (7), and a data store (from the main storage) is assigned to the virtual machine (8). A series of requests by the system administrator inserts necessary software for the VM that ends with creating an account with a username and password (9) in the VMWare (10) and saving it in the storage (11 and 12). This triggers (13) the creation of an acknowledgment with account details that flow to the user (14).

The minimum VM software involves the following:

- Setting the operating system (OS; 16) of the virtual machine that is downloaded (17) from the main storage (18) to the VM storage (19).

- Creating a network connection (20) through which the network system receives a request (21) that triggers processing of a communication module (22) to generate a user communication module in the virtual machine (23)

Note that this TM representation may have some errors because of the lack of clarity and completeness in the given manual diagram. If this is the case, then the TM diagram can easily be modified accordingly.

We claim that the resulting description is more systematic than diagrams (e.g., Fig. 2 in typical computer manuals). Systematization refers to a logical and orderly depiction of event occurrences, as will be described next when we analyze behavior in the TM machine.

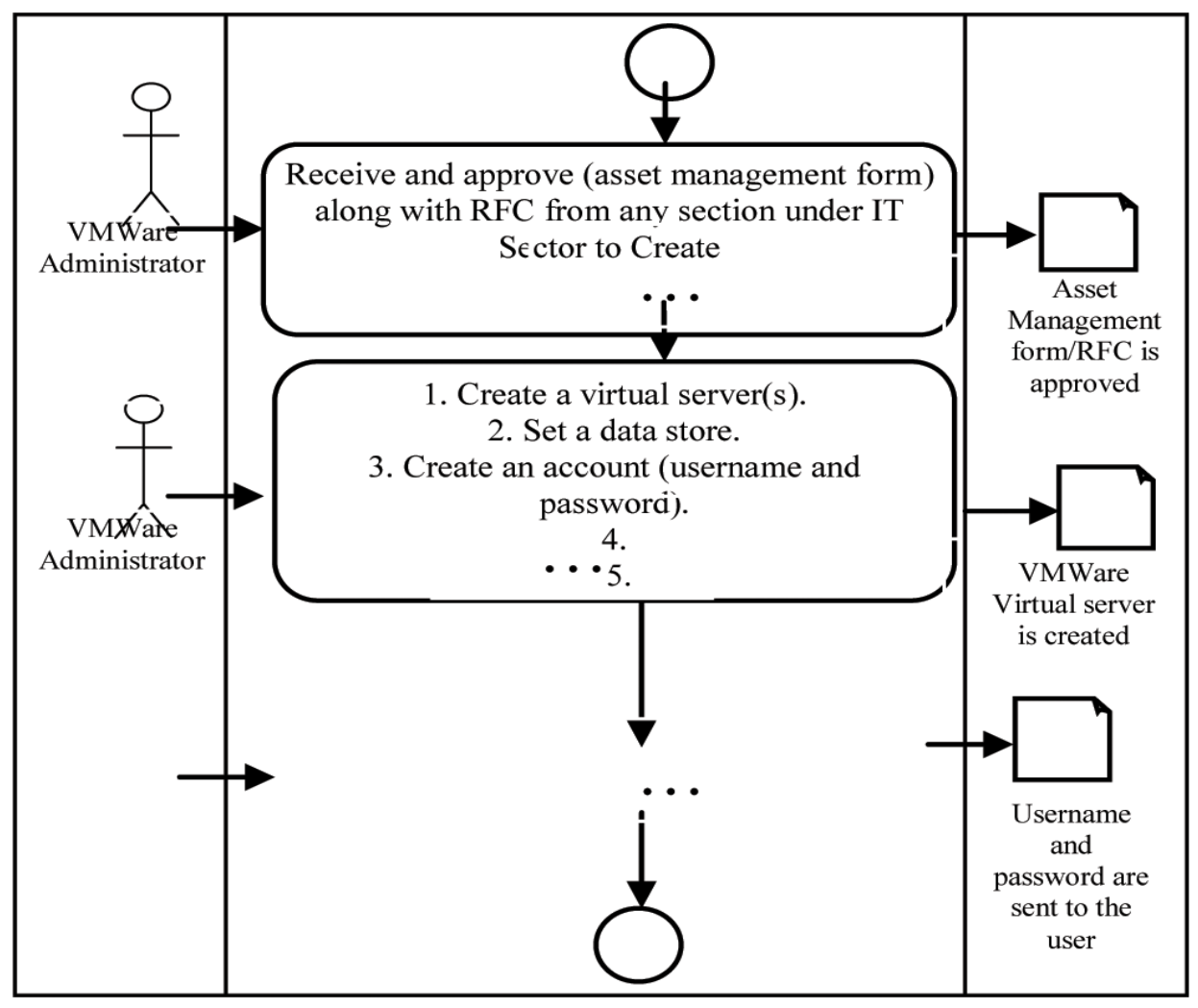

Figure 2. Description of the VMWare virtual server's creation, as given in the current computer manual (redrawn, partially from [24])

Additionally, the TM can be understood by non-experts; hence, it is a suitable tool for training, documentation, and communication. It is an important tool in the areas of maintenance/operations and management.

\subsubsection{Dynamic Machine}

The TM embeds the captured behavior of the modeled system in terms of events. Behavior is a process that: 


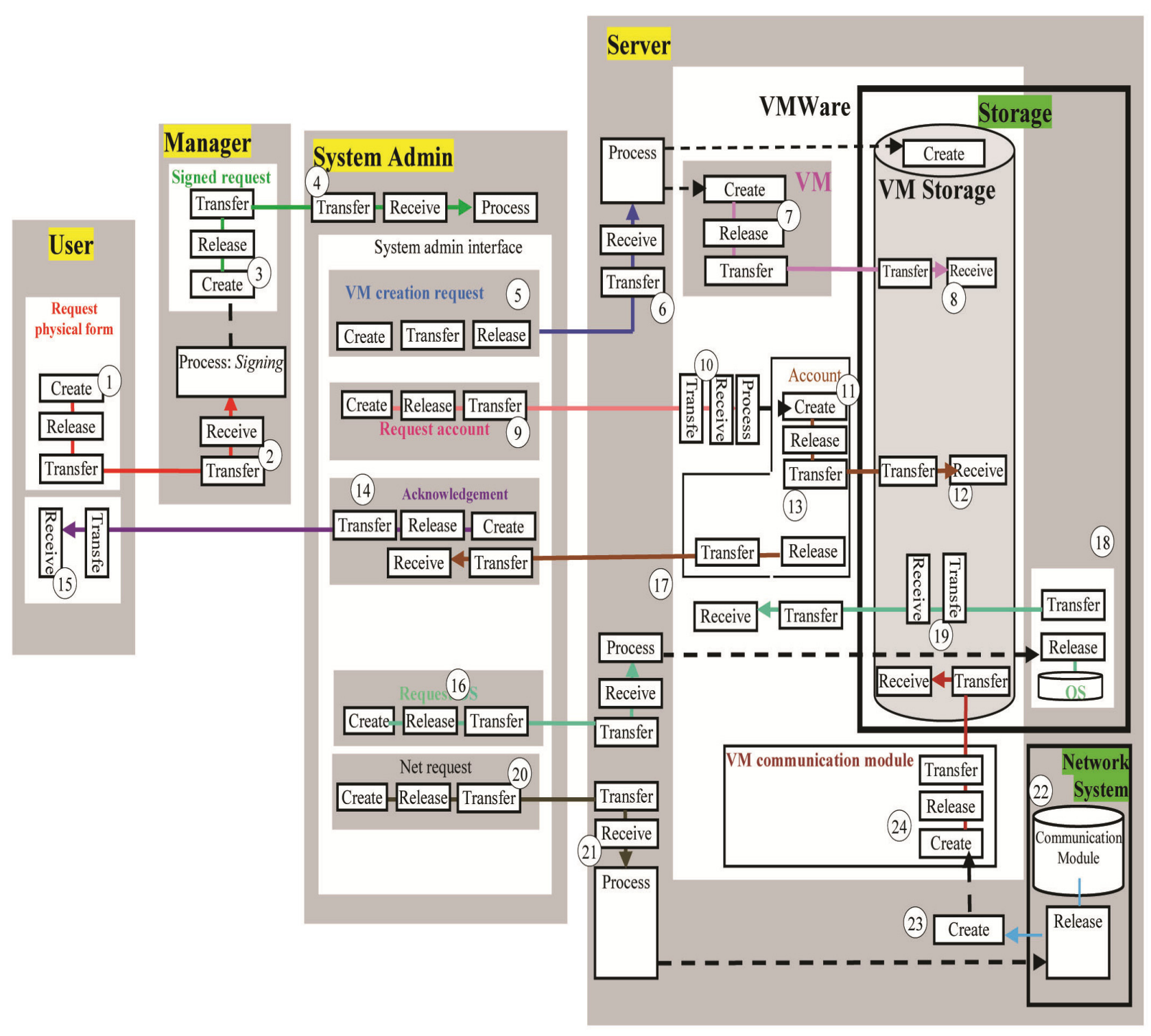

Figure 3. The TM representation describing the process of creating a VMWare

- Breaks the machines into sub-machines;

- Breaks machines into pieces; and

- Maps each sub-machine to things of time.

Accordingly, an event is constructed from a region (sub-machine), a time machine, and a machine of the event itself. Fig. 4 shows three sub-diagrams (the thick arrows denote the mappings) of the static description and their corresponding events. For the sake of simplification, we will represent each event by its region only (sub-machine). Note that time is a machine; that is, it can be created, processed, released, transferred, and received.

Accordingly, this section identifies events in the TM. This is an additional documentation tool that provides a picture of the system's behavior, which may be utilized in managing and controlling processes. This is analogous to an algorithm. 


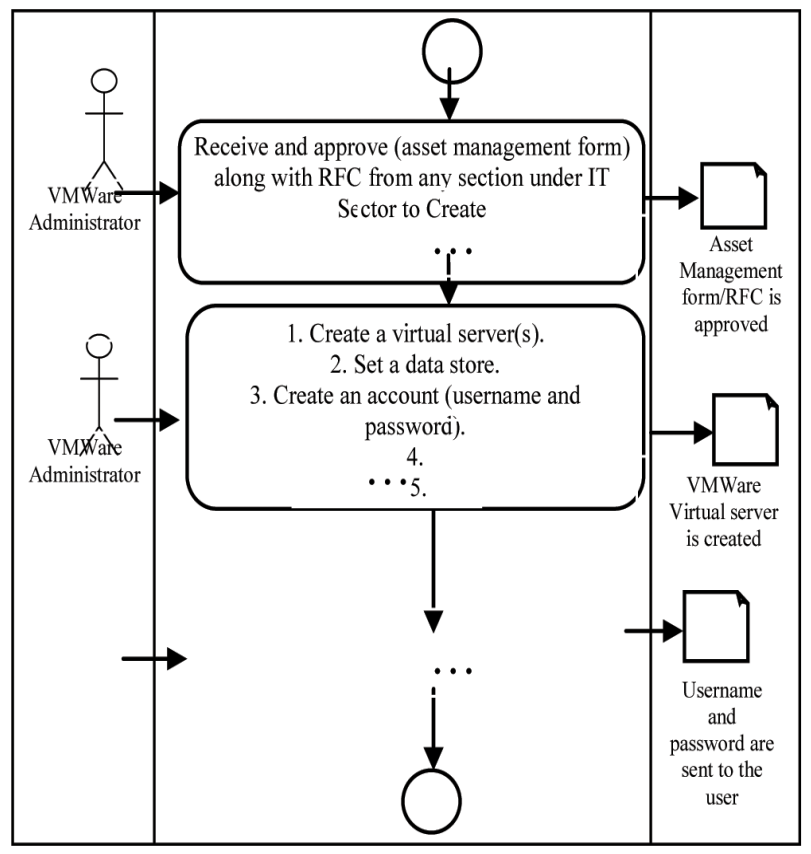

Figure 4. Three sub-diagrams of the static representation of Figure 3 and their corresponding events

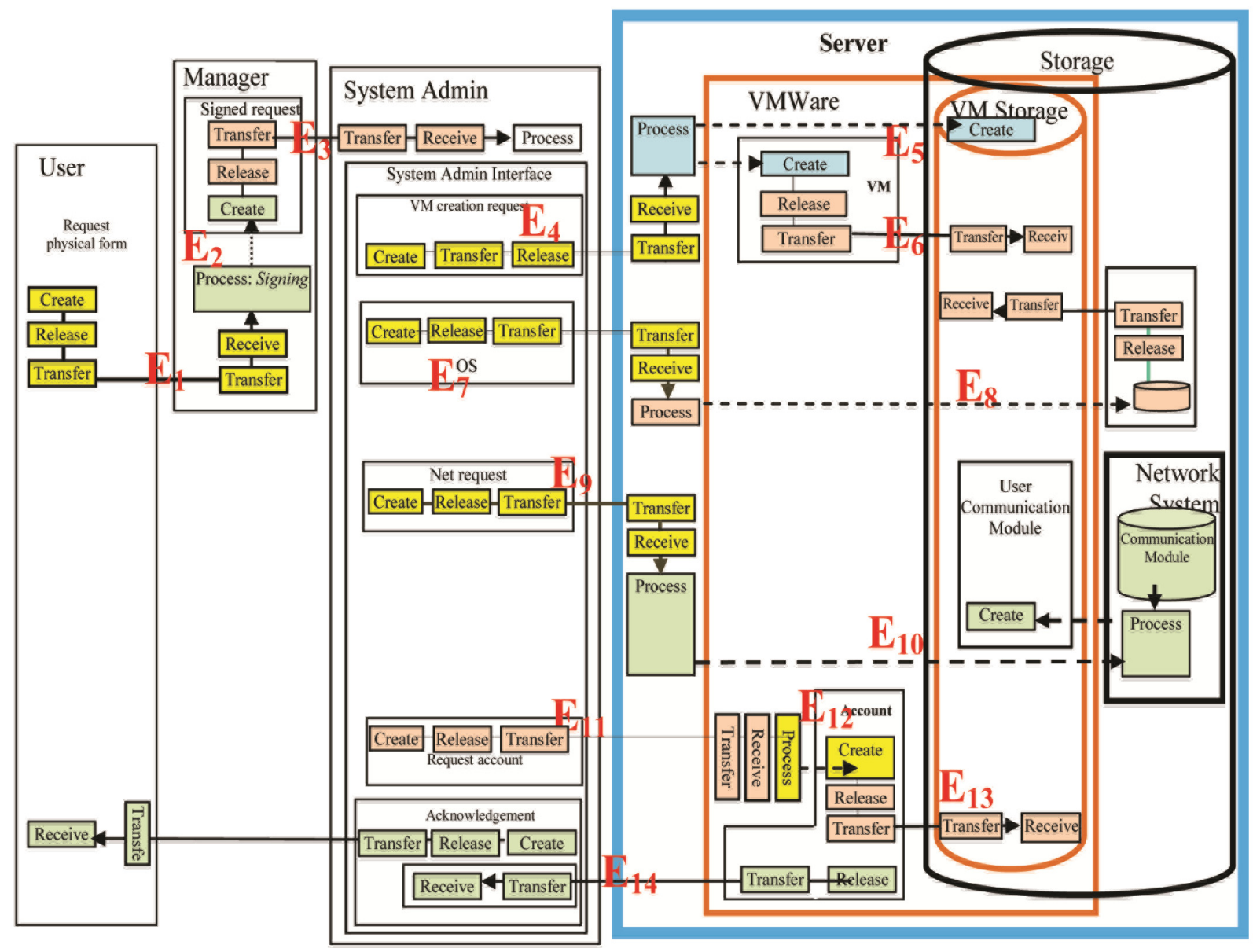

Figure 5. The TM representation of the events of the process of creating a VMWare virtual server 
Event $1\left(\mathrm{~V}_{1}\right)$ : The manager receives a request form.

Event $2\left(\mathrm{~V}_{2}\right)$ : The manager signs the form.

Event 3: $\left(\mathrm{V}_{3}\right)$ : The system admin receives the request for a $\mathrm{VM}$.

Event $4\left(\mathrm{~V}_{4}\right)$ : The manager requests the system (on the server) to create the VMWare, and the request is received in the server

Event $5\left(\mathrm{~V}_{5}\right)$ : The VMWare and its storage are created.

Event $6\left(\mathrm{~V}_{6}\right)$ : The $\mathrm{VM}$ is saved to the storage.

Event $7\left(\mathrm{~V}_{7}\right)$ : The system admin requests to store the OS to the VM.

Event $8\left(\mathrm{~V}_{8}\right)$ : The server stores the OS on the VM.

Event $9\left(\mathrm{~V}_{9}\right)$ : The system admin requests the creation of a network connection.

Event $10\left(\mathrm{~V}_{10}\right)$ : The network communication module is put into the VM.

Event $11\left(\mathrm{~V}_{11}\right)$ : The system admin requests the creation of an account.

Event $12\left(\mathrm{~V}_{12}\right)$ : The account is created.

Event $13\left(\mathrm{~V}_{13}\right)$ : The account is saved in storage.

Event $14\left(\mathrm{~V}_{14}\right)$ : Acknowledgment includes the fact that the account is sent to the user.

Fig. 6 shows the chronology of these events that reflects the control flow.

\subsection{Backup of Open System Servers}

As in the previous process, this process in the manual involves a diagram (Figure 7) with no text. The process is given the title "Netbackup Utility for OS Backup of Open System Servers" [24]. Objective: To back up the OS for open system servers.

Figure 8 shows the corresponding TM representation. In the figure, the system admin sends an email (25) to the netbackup admin (26) to add the new VM under the backup duration cycle. The netbackup admin then:

- Downloads (27) a netbackup client agent (28) on the VMWare storage (29); and

- Downloads a new backup policy (30) with a daily/weekly/monthly schedule configured to run automatically, as per the schedule (31), and this configuration is saved to the VM storage (32).

After completing this, the VM backup agent turns the clock ON (33) that triggers processing the time until reaching backup time (34). This turns the clock OFF and triggers the VM backup agent (35) to save the whole VMWare (36) on tapes. Accordingly, the netbackup admin creates a backup report and sends it to the system admin (37).

Figure 9 shows the events in the netbackup process.

Event $15\left(\mathrm{~V}_{15}\right)$ : The system admin requests the creation of a backup system for the new VMWare, which is received by the netbackup admin.

Event $16\left(\mathrm{~V}_{16}\right)$ : The netbackup admin processes the request.

Event $17\left(\mathrm{~V}_{17}\right)$ : The server backup agent is activated to create the VM backup agent.

Event $18\left(\mathrm{~V}_{18}\right)$ : The backup policy is processed, and the backup timing is created.

$62 \quad$ Progress in Computing Applications Volume 7 Number 2 September 2018 
Event $19\left(\mathrm{~V}_{19}\right)$ : The VM backup agent is created and put on the VM.

Event $20\left(\mathrm{~V}_{20}\right)$ : The VM backup agent is stored.

Event $21\left(\mathrm{~V}_{21}\right)$ : The backup time is created.

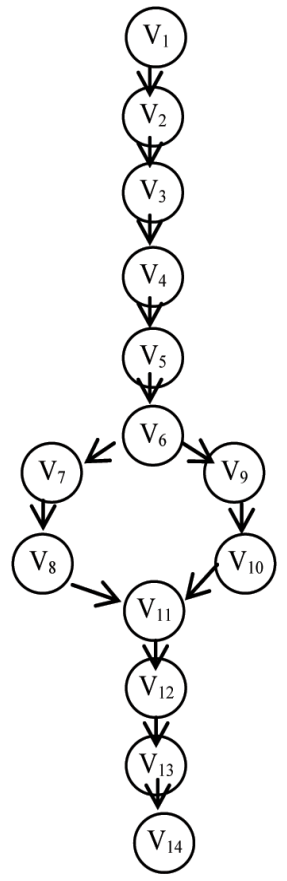

Figure 6. The chronology of events in the TM representation.

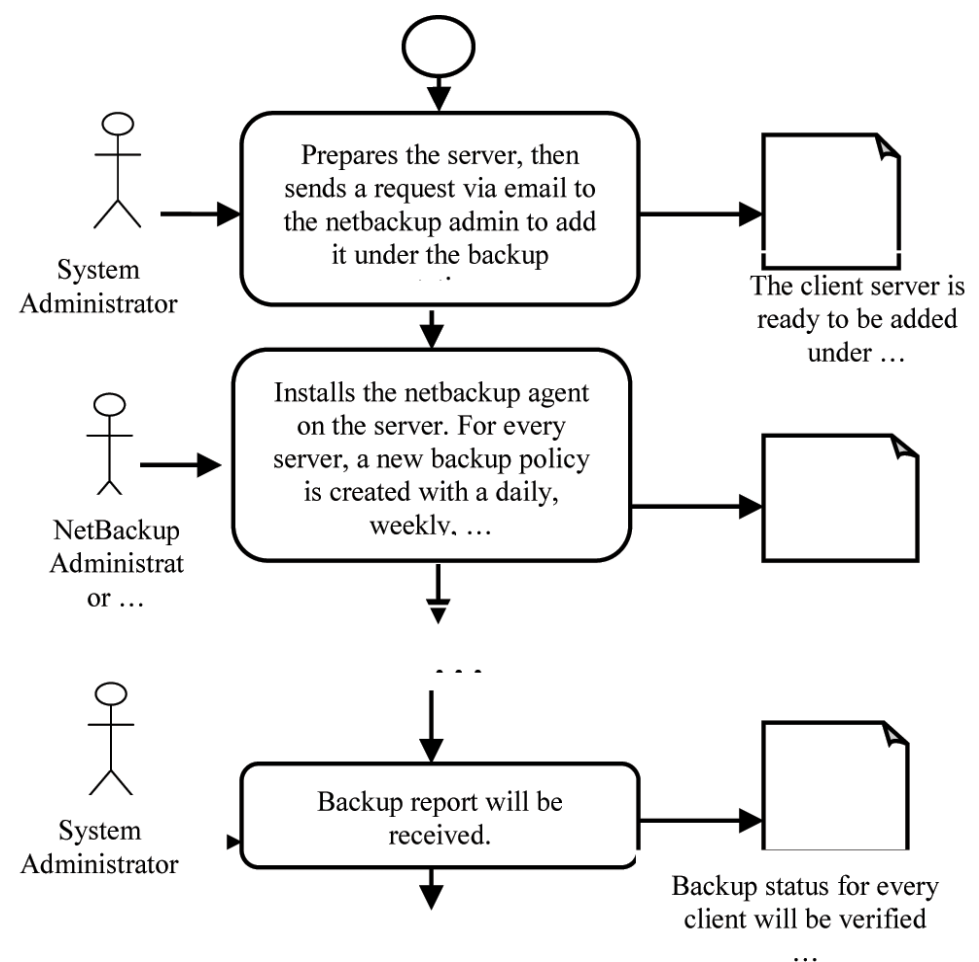

Figure 7. Description of netbackup utility for OS backup of open system servers (re-drawn, partial from [24]) 


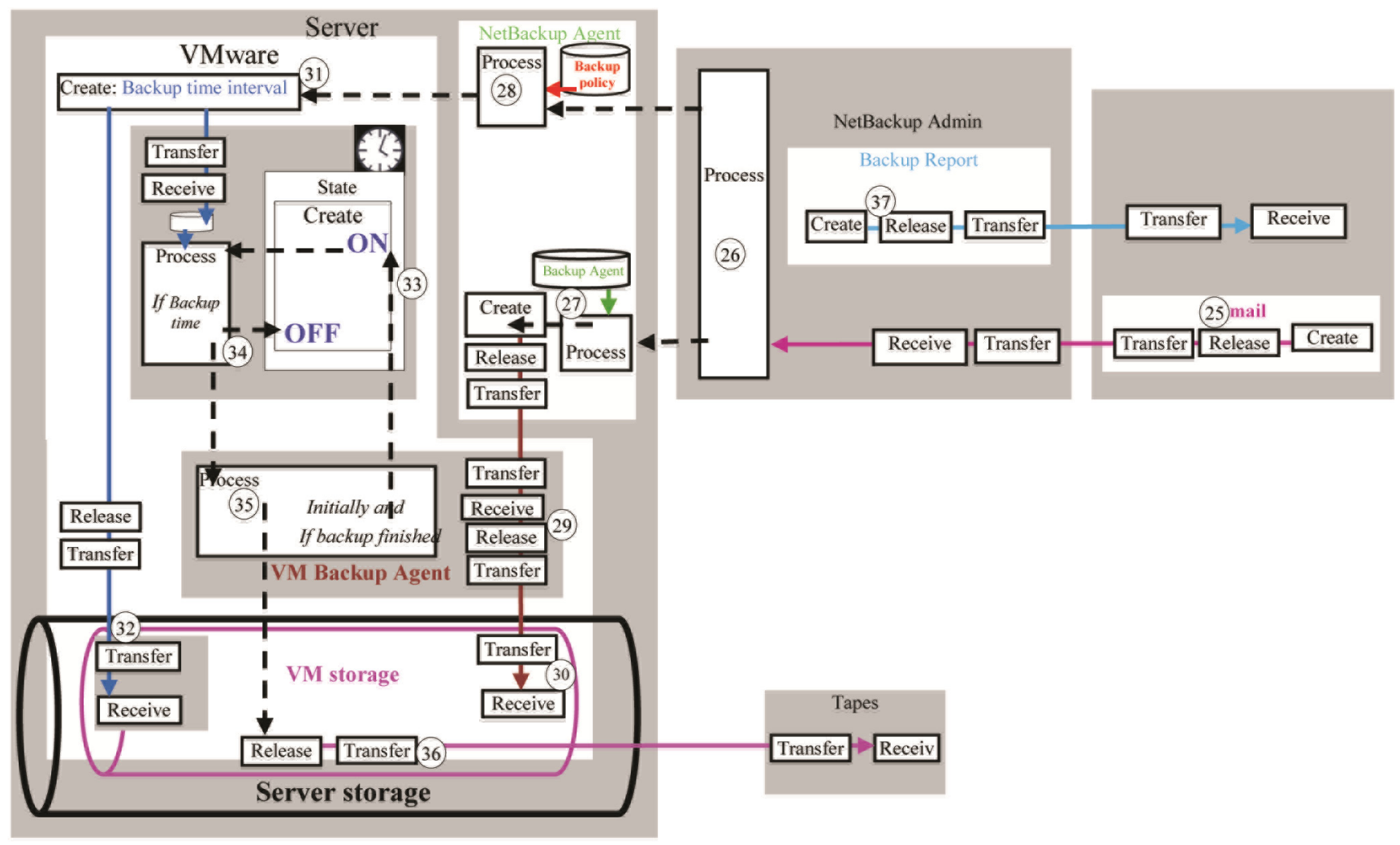

Figure 8 . The TM representation of the process Netbackup Utility

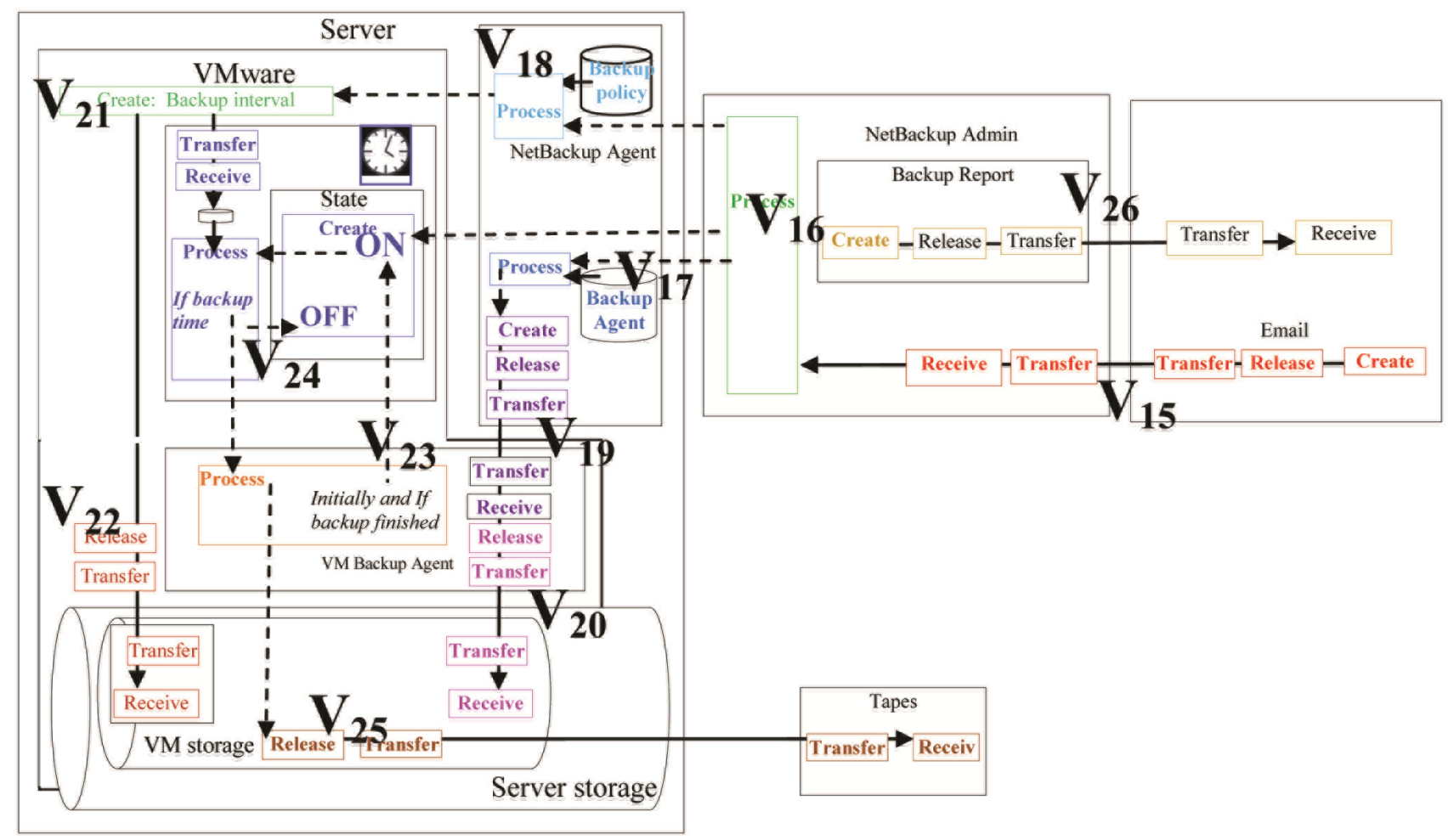

Figure 9. The TM representation of events of the process Netbackup Utility 
Event $22\left(\mathrm{~V}_{22}\right)$ : The backup time is stored.

Event $23\left(\mathrm{~V}_{23}\right)$ : The VM backup agent triggers the clock $\mathrm{ON}$ so that it monitors the time until the backup time.

Event $24\left(\mathrm{~V}_{24}\right)$ : The VM backup agent is activated to process the backup. Also, the clock is turned OFF.

Event $25\left(\mathrm{~V}_{25}\right)$ : The VM data are stored on tapes.

Event $26\left(\mathrm{~V}_{26}\right)$ : At the end of the backup, the agent turns the clock ON.

Event $27\left(\mathrm{~V}_{27}\right)$ : A backup report is created and sent to the system admin.

Figure 10 shows the chronology of events. Note that events 23, 24, and 25 are repeated according to the specified backup downloading.

Contrasting the TM diagrams with the ad hoc diagrams in Figures 2 and 7, side by side, shows the difference in terms of the diagram's systemization based on TMs that have led to less dependency on English.

\section{Conclusion}

The use of process documentation through diagrams would allow businesses to react more quickly against competition and threats as well as make business processes and employees more efficient and effective [9].

We apply a new modeling technique, TM, to document processes systematically. TM can be utilized uniformly at different stages of system development, from requirement specification to the user interface. Using the TM modeling technique as a documentation tool is a promising field that needs in-depth investigation.

The TM diagrams may look complex; however, they can be simplified by lumping the details together or omitting stages. Figure 11 shows a simplification of the TM representation that describes the process of creating a VMWare (Figure 8). Nevertheless, the underlying TM schema remains the reference for any further uses, such as for analysis and documentation.

Further research will work on other types of processes. Many issues remain to be clarified; however, this paper demonstrates the potential feasibility of this documentation approach, which can be utilized in technical manuals.

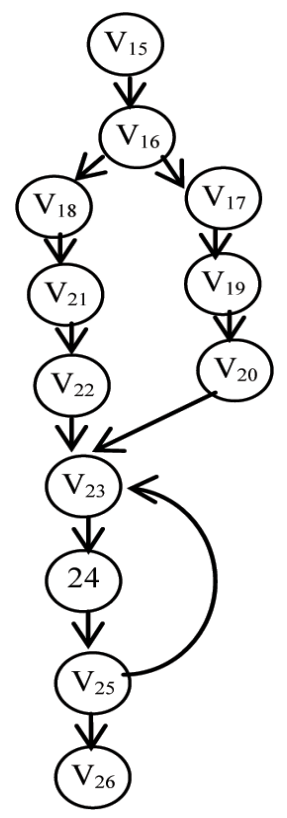

Figure 10. Chronology of events 


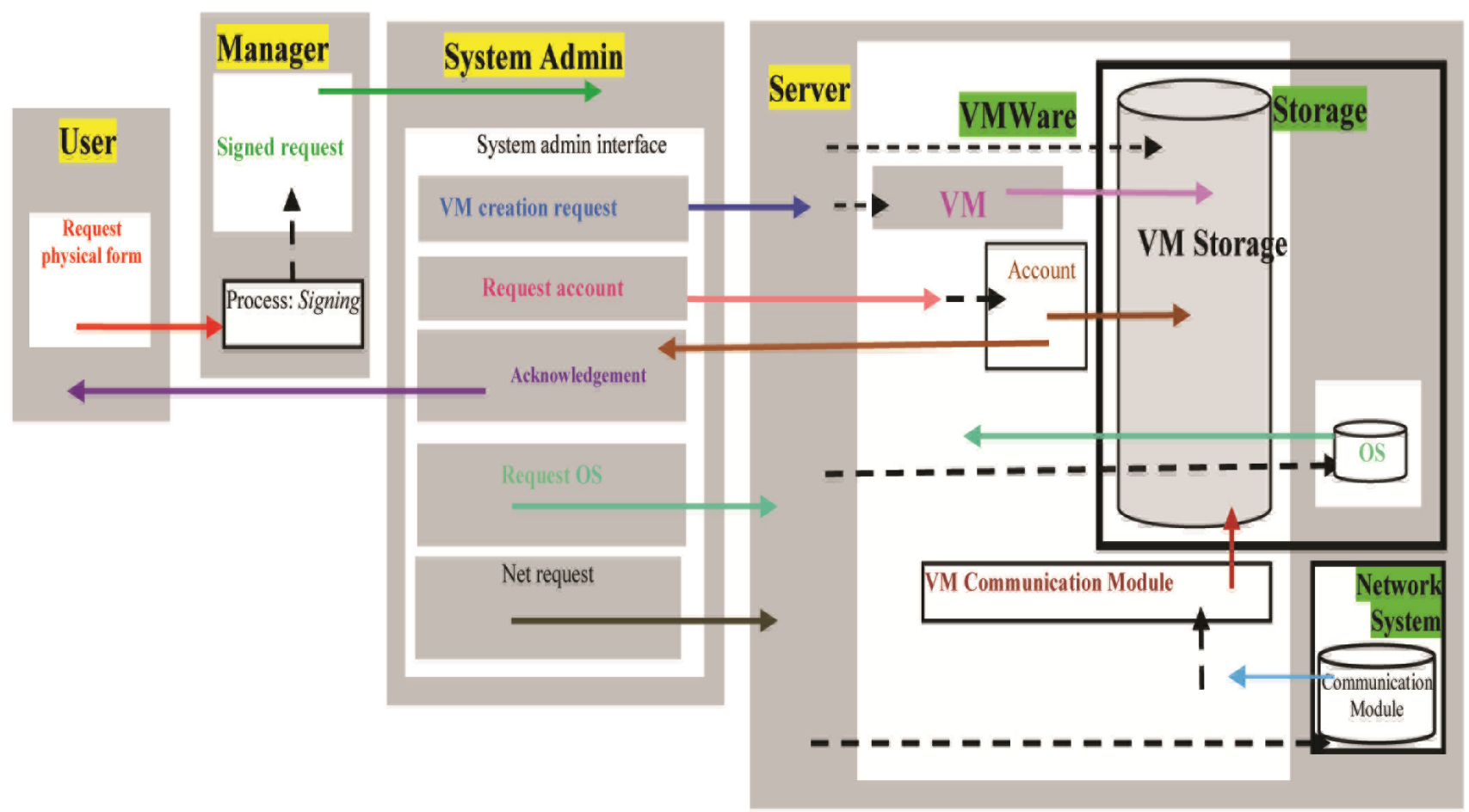

Figure 11. Simplified TM representation where stages are deleted

\section{References}

[1] Groth, P., Miles, S., Moreau, L. (2009). A model of process documentation to determine provenance in mash-ups, $A C M$ Transactions on Internet Technology (TOIT), 9 (1) 3:1-3:31.

[2] Mosse, D. (1998). Process documentation research and process monitoring, In: Development as Process: Concepts and Methods for Working with Complexity, D. Mosse, J. Fennigton and A. Rew, Eds. London: Routledge, 31-53.

[3] Z. Quraishy, "Process documentation," Presentation, Dept. of Informatics, University of Oslo, Norway, http://www.google.com/

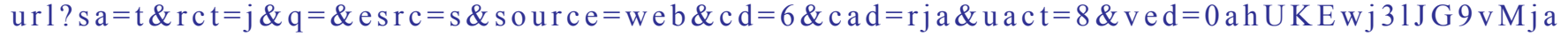
AhXSZ1AKHUz0D7cQFghMMAU\&url=http\%3A\%2F\%2Fwww.uio.no\%2Fstudier $\% 2 F e m n e r \% 2 F m a t n a t \% 2 F i f i \% 2 F I N F 5730 \% 2 F h 04 \% 2 F$ undervisningsmateriale\%2FProcessDocumentation.ppt\&usg=AOvVaw1fZ3siM9w-zUVDawvUmWyT.

[4] Lucid Software Inc. (2018). What is process documentation?, https://www.lucidchart.com/pages/process-documentation.

[5] James, I. (2017). Process documentation guide, The Process Consultant, September 8, https://theprocessconsultant.com/ process-documentation/.

[6] Hammer, M. (1996). Beyond Reengineering. New York: HarperCollins Publishers, Inc., 1996.

[7] Bal, J. (1998). Process analysis tools for process improvement. The TQM Magazine, 10, 342-354.

[8] Ene, M., Persson, C. (2005). The process of process documentation: A case study at Volvo IT, master's thesis, School of Economics and Commercial Law, University of Gothenburg, Department of Informatics, June.

[9] Aschwanden-Granfelt, S. (2007). Process flow documentation: A flowchart guide for micro \& small business, thesis, degree program: international business, April .

[10] L. Westfall. (2001). How to create useful software process documentation, International Conference on Software Quality, Pittsburgh, PA, 11.

[11] OMG. (2018). Object management group business process model and notation, 2.0, http://www.bpmn.org/. 
[12] UML. (2018). What is UML, 2018, http://www.uml.org/.

[13] IEEE-1320: IEEE Standards Software Engineering, 4, IEEE.

[14] Humphrey-89: Watts Humphrey and Marc Kellner, Software Process Modeling: Principles of Entity Process Models, http:// www.sei.cmu.edu/publications/documents/89.reports/89.tr.002.html.

[15] Al-Fedaghi, S., Al-Huwais, N. (2018). Toward modeling information in asset management: Case study using Maximo, $4^{\text {th }}$ International Conference on Information Management (ICIM2018), Oxford, UK, May 25-27, 2018.

[16] Al-Fedaghi, S., Warsame, N. (2018). Provenance as a machine, International Conference on Information Society (i-Society), Dublin, Ireland, July 15-18.

[17] Al-Fedaghi, S., Warsame, N. (2018). Provenance as a machine, International Conference on Information Society (i-Society), Dublin, Ireland, July 15-18.

[18] Al-Fedaghi, S., Manal Alsharah. (2018). Modeling IT processes: A case study using Microsoft Orchestrator, $4^{\text {th }}$ IEEE International Conference on Advances in Computing and Communication Engineering, Paris, France, June 22-23.

[19] Al-Fedaghi, S., Mousa Alsulaimi. (2018). Re-conceptualization of IT services in banking industry architecture network, $7^{\text {th }}$ IEEE International Conference on Industrial Technology and Management (ICITM 2018), Oxford University, Oxford, UK, March 7-9.

[20] Heidegger, M. (1975). The thing, in Poetry, Language, Thought, A. Hofstadter, trans. New York: Harper \& Row, 161-184.

[21] Latour, B. (2004). Why has critique run out of steam?, Critical Inquiry, 30.

[22] Carreira, J. (2011). Philosophy is not a luxury, blog, March 2, 2011, https://philosophyisnotaluxury.com/2011/03/02/to-thinga-new-verb/

[23] Fry, T. (2006). Object-thing philosophy and design: Review of B. Latour and P. Weibel making things public; G. Harman toolbeing and guerrilla metaphysics; Peter-Paul Verbeek what things do, Design Philosophy Papers, 4 (1) 21-39, http://dx.doi.org/ 10.2752/144871306X13966268131316.

[24] Imbusch, O., Langhammer, F., von Walter, G. (2004). Ercatons: Thing-oriented programming, $5^{\text {th }}$ Annual International Conference on Object-Oriented and Internet-Based Technologies, Concepts, and Applications for a Networked World, Net.ObjectDays 2004, Erfurt, Germany, September 27-30.

[25] Bank Manual: Procedures Manual, Date: October 2011, 34, Section: Systems and Operations, Title: Create VMWare Virtual Server. 